OPEN ACCESS

Edited by:

Thomas Bartholomäus Brück,

Technical University of Munich,

Germany

Reviewed by:

Noha M. Mesbah,

Suez Canal University, Egypt

Pabulo Henrique Rampelotto,

Federal University of Rio Grande do

Sul, Brazil

*Correspondence:

Paola Durán

paola.duran@ufrontera.c

Specialty section

This article was submitted to

Bioprocess Engineering,

a section of the journal

Frontiers in Bioengineering and

Biotechnology

Received: 12 February 2020

Accepted: 11 May 2020

Published: 04 June 2020

Citation:

Rodriguez $R$ and Durán P (2020)

Natural Holobiome Engineering by Using Native Extreme Microbiome

to Counteract the Climate Change

Effects.

Front. Bioeng. Biotechnol. 8:568

doi: 10.3389/fbioe.2020.00568

\section{Natural Holobiome Engineering by Using Native Extreme Microbiome to Counteract the Climate Change Effects}

\author{
Rodrigo Rodriguez ${ }^{1}$ and Paola Durán ${ }^{1,2 *}$ \\ ${ }^{1}$ Biocontrol Research Laboratory, Universidad de La Frontera, Temuco, Chile, ${ }^{2}$ Scientific and Technological Bioresource \\ Nucleus, Universidad de La Frontera, Temuco, Chile
}

In the current scenario of climate change, the future of agriculture is uncertain. Climate change and climate-related disasters have a direct impact on biotic and abiotic factors that govern agroecosystems compromising the global food security. In the last decade, the advances in high throughput sequencing techniques have significantly improved our understanding about the composition, function and dynamics of plant microbiome. However, despite the microbiome have been proposed as a new platform for the next green revolution, our knowledge about the mechanisms that govern microbe-microbe and microbe-plant interactions are incipient. Currently, the adaptation of plants to environmental changes not only suggests that the plants can adapt or migrate, but also can interact with their surrounding microbial communities to alleviate different stresses by natural microbiome selection of specialized strains, phenomenon recently called "Cry for Help". From this way, plants have been co-evolved with their microbiota adapting to local environmental conditions to ensuring the survival of the entire holobiome to improve plant fitness. Thus, the strong selective pressure of native extreme microbiomes could represent a remarkable microbial niche of plant stress-amelioration to counteract the negative effect of climate change in food crops. Currently, the microbiome engineering has recently emerged as an alternative to modify and promote positive interactions between microorganisms and plants to improve plant fitness. In the present review, we discuss the possible use of extreme microbiome to alleviate different stresses in crop plants under the current scenario of climate change.

\section{Keywords: microbiome, climate change, microbiome engineering, sustainable agriculture, microbiome transferring, crop productivity}

\section{INTRODUCTION}

According to the Organization for Economic Cooperation and Development (OECD), agriculture is considered one of the most essential economic, social and environmental activities for human beings. Until now, agricultural and livestock products has been able to respond to the growing world demand. However, it is estimated that by 2050 the world population would reach 9.7 billion people and that crop productivity should increase approximately $60-100 \%$ to meet this demand 
of food (Hunter et al., 2017; United Nations, 2019). This is due to climate change and climate-related disasters have a direct impact on biotic and abiotic factors that govern agroecosystems, compromising the global food security (Challinor et al., 2014; FAO, 2016a; Dresselhaus and Hückelhoven, 2018; Cavicchioli et al., 2019; Raza et al., 2019). For this reason, the new green revolution is required to achieve future food security, where new concepts and approaches are needed to achieve a more sustainable development of agriculture.

To date, many studies have investigated biotechnological solutions to counteract the negative effect on crop yield. Since the last 20 years, isolation through culture-dependent techniques and inoculation of cultivable Plant Growth-Promoting Microorganisms (PGPM) have substantially improved plant fitness under laboratory conditions (Adesemoye et al., 2008; Barra et al., 2016, 2019; Viscardi et al., 2016). However, the low extraction efficiency of the culture-dependent methods $(<1 \%)$ and the limited establishment of the microorganisms under field conditions, represent an important limitation for their massive use (Alabouvette et al., 2009; Toju et al., 2018b). Nowadays, the advances in meta-omics have significantly improved our understanding about the composition, function and dynamics of cultivable and non-cultivable microorganisms in agroecosystems (Esposito et al., 2016; Meena et al., 2017; Wang et al., 2017; Toju et al., 2018a), allowing a better understanding of the microbiomes associated in different ecosystems, the participation of each member of these complex microbial communities and the role of keystone microbial taxa. However, the mechanisms that govern microbe-microbe and microbe-plant interactions are incipient and few studies have used this ability to transfer microbiomes (e.g., performing soil transplants) to improve crop production. In contrast, in human health the manipulation and transplants of microbiomes or core microbiomes is currently applied to solve diseases (Borody and Khoruts, 2012; Kelly et al., 2016; Paramsothy et al., 2017; Lev-Sagie et al., 2019).

Our current knowledge about adaptation of plants to environmental changes not only suggests that plants can adapt or migrate, but can also interact, modify and select specific microbial communities to mitigate the negative effect of different stresses, phenomenon recently called "Cry for Help" (Bakker et al., 2018; Berendsen et al., 2018; Carrión et al., 2019; Li X. et al., 2019; Rolfe et al., 2019). Therefore, the modification of these interactions between microorganisms and plants could represent a promising alternative to mitigate the negative effects of climate change on food crops. In this context, microbiome engineering has recently emerged as an alternative to promote positive interactions between microorganisms and host plants (Mueller and Sachs, 2015; Sheth et al., 2016; Foo et al., 2017; Timmusk et al., 2017; Trivedi et al., 2017; Hussain, 2019). Recently, Jochum et al. (2019b) have performed host-mediated microbiome engineering to attribute drought resistance in wheat plants, which demonstrates the potential for modification of native microbiomes to attribute crop resistance. Thus, the transfer of whole microbiomes to improve crop yields under different stress situations could represent an unparalleled advance to start a new revolution in the bioinoculants development (Santoyo et al., 2017; Woo and Pepe, 2018). In this context, microbiomes of extreme environments could represent an unequaled source of stress-ameliorating due to the strong selective pressure suffered by microorganisms in extreme environments (Durán et al., 2019). In this review, we highlighted the main characteristics of natural microbial engineering focalizing in extreme microbiomes to improve crop resistance to different stresses in the current scenario of climate change events.

\section{CLIMATE CHANGE AND CROP PRODUCTIVITY: IMPACTS AND PRIORITY RESEARCH}

Climate change and catastrophic events have negatively influenced the plant physiology (Challinor et al., 2014; Wang et al., 2018; Raza et al., 2019), generating important economic losses in the agri-food sector in the last decade (FAO, 2016a; Huong et al., 2018). In this context, drought stress is the most worrisome stress in the current scenario of climate change (FAO, 2016b). Studies conducted with heat and drought stresses (combined stresses) on Solanum lycopersicum, showed that drought stress has a predominant negative effect on plant survival (Zhou et al., 2017, 2019). For example, at morphophysiological level, it is known that plants decrease leaf area and stem length, reduce leaf water potential, decrease stomatal conductance, decrease net photosynthetic rate and loss of turgor and osmotic adjustment as a consequence of lack of water with a concomitant reduction of plant productivity (Jangid and Dwivedi, 2016; Hussain et al., 2018; Kumar et al., 2018). From a biochemical point of view, plants are able to increase the activity of antioxidant enzymes (Superoxide dismutase, SOD; Catalase, CAT; and Peroxidase, POD), temporarily reduce photochemical efficiency, reduce the accumulation of reactive oxygen species (ROS), decrease Rubisco efficiency and increase the accumulation of Proline, Polyamine and Trealose (Ammar et al., 2015; Kumar et al., 2018). At molecular level, plants can increase the expression of the biosynthetic genes of the phytohormone abscisic acid (ABA), synthesize specific proteins such as dehydrins and late embryogenesis abundant (LEA) proteins and increase the expression of transcription factors such as DREB, WRKY, and NAC that produce resistance against drought stress (Liu G. et al., 2014; Liu Y. et al., 2014; Sun et al., 2015; Yang et al., 2017; Kumar et al., 2018). To date, ABA is perhaps the most important phytohormone in the regulation of water use by plants under drought conditions. It is currently known that $\mathrm{ABA}$ is a key intermediary for the control of stomatal closure under water scarcity conditions (Mishra et al., 2006; Mega et al., 2019) and is also a signaling intermediary that induces the expression of genes such as $R D 22, R D 29 A, R D 29 B$, KIN2, RAB18, and PYL8 that play an important role in response and tolerance against dehydration (Abe et al., 1997; Ramírez et al., 2009; Cutler et al., 2010; Yao et al., 2012; Lim et al., 2013). In the last decades, interaction between UVs (UV-B) exposition and drought stress in plants has been evidenced. For example, Alexieva et al. (2001) showed that despite UV-B radiation has stronger stress effectors than drought. However, both acted synergistically in order to induce protective mechanisms to 
reduce the stress in wheat and pea plants. In contrast, Novotná et al. (2016), shown that drought led to a significant reduction of above-ground biomass, particularly under ambient UV radiation. Thus, the combined effect of drought and UV radiation which may result in an enhance or vice-versa alleviation of drought impact. This is important to consider due to Bais et al. (2015) estimated that by the end of the 21 st century the most populated areas of the northern hemisphere could increase $10-20 \%$ in UV radiation. Sunlight provides the energy necessary for plant growth through photosynthesis, however, high energy light and, in particular, UV-A (315-400 nm) and UV-B (280-315 nm) can produce damage to plants through structural modifications in DNA, protein denaturation, damage to membranous organelles (chloroplasts, mitochondria and nucleus) and cause oxidative stress (Müller-Xing et al., 2014; Sharma et al., 2017; Tossi et al., 2019). UV-B has been considered as the most harmful type of radiation for plants, morphological changes have been observed as thicker leaves, shorter petioles and lower chlorophyll content (Zhu et al., 2010; Inostroza-Blancheteau et al., 2014; Robson et al., 2015). Studies conducted in recent years show that high UV-B irradiation can even decrease $\mathrm{CO}_{2}$ assimilation, decrease photochemical efficiency of photosystem II (PSII), reduce electron transport rate (ETR) and limit the productivity of some crops (Basahi et al., 2014; Wang et al., 2015; GonzálezVillagra et al., 2020). Our current knowledge has determined that plants can counteract the negative effect of UV-B through a series of morphological and molecular changes, such as, the biosynthesis of phenolic acids and flavonoids induced by a UV-B photoreceptor called UV RESISTANCE LOCUS 8 or UVR8 (Coffey et al., 2017; Yang et al., 2018; Kondou et al., 2019; Tossi et al., 2019). Nowadays, different research groups have proposed novel biotechnological methods to mitigate the effect of abiotic stress on agricultural crops, among them the use of PGPM are widely studied (Calvo-Polanco et al., 2016; Vurukonda et al., 2016; Ullah et al., 2017; Etesami and Maheshwari, 2018; Bernardo et al., 2019; Bahadur et al., 2019; Mathur et al., 2019; Mickan et al., 2019). Several studies related with PGPM isolated from extreme environment has been widely reported (Table 1), such is the case cold desert such as Antarctic, arid desert, volcanoes and hydrothermal environments. For example, Timmusk et al. (2014) have used Bacillus thuringiensis AZP2 and Paenibacillus polymyxa B isolated from hostile environments to induce drought resistance to wheat crops. Moreover, Lim and Kim (2013) have used Bacillus licheniformis K11 to induce drought resistance through the action of Auxins and ACC deaminase produced by this strain. Furthermore, Khan et al. (2018) used PGPM isolated from the rhizosphere of rainfed area (Karak) in Pakistan (Bacillus cereus and Planomicrobium chinense) combined with salycilic acid to improve Helianthus annuus resistance. Recently, Jochum et al. (2019a) isolated and characterized two bacterial strains (Bacillus sp. and Enterobacter sp.) with a high potential to lag the effects of drought on wheat (Triticum aestivum) and corn (Zea mays) seedlings. In the case of arbuscular mycorrhizal fungi (AMF), for example, Meddich et al. (2015) used different mycorrhizal fungi to improve the performance of Phoenix dactylifera against water deficit, finding a significant increase in peroxidase and polyphenolxidases in the roots of mycorrhized palms enhancing the survival of plant in these stress conditions. In addition, Li J. et al. (2019) have used symbiote fungi to confer resistance to C3 grass Leymus chinensis and in C4 grass Hemarthria altissima under water deficit condition. Our current knowledge about the role of AMFs to help plants withstand drought stress is mainly involved in direct absorption of water by hyphae and their transfer to the host plant, increasing water content and eliminating the generation of ROS and the production of biomolecules and enzymes with antioxidant capacity (Huang et al., 2017; Liu C. Y. et al., 2017; Liu Y. et al., 2017; Bahadur et al., 2019). In the case of biotechnological tools to mitigate the damage caused by UVs radiation, only preliminary studies have been highlighting the important role of phyllosphere microorganisms, which has been co-evolved on the surface of plant leaves, developing defense mechanisms to counteract the harmful effects of UV-B. For example, it has been shown that Clavibacter michiganensis present on the surface of Arachis hypogaea leaves are highly resistant to UV-B radiation due to carotenoid production and the expression of CAT and SOD (Jacobs and Sundin, 2001; Jacobs et al., 2005). Additionally, Enterobacter cloacae isolated from the rice surface also has a great capacity to resist UV-B radiation due to the expression of certain proteins (Kumar et al., 2016). Despite biostimulant-based technologies are promising to improve crop yields (Melusá et al., 2012; Pratap et al., 2016), the use of PGPM is largely limited by poor success in field conditions. This limitation is mainly due to the abundance and functional diversity of native soil microorganisms, allowing them to occupy most of the available ecological niches, so that attempts to introduce new microorganisms are limited (Felici et al., 2008; Alabouvette et al., 2009; Martinez-Viveros et al., 2010; Trabelsi et al., 2011; Lindemann et al., 2016; Toju et al., 2018b). The niche overlap between an inoculant and resident microorganisms seems to be limited even with resident microorganisms that are phylogenetically related to the inoculant (Castro-Sowinski et al., 2007). However, some studies showed that inoculation with microbial consortia is a more effective approach than inoculation with a single strain, since microorganisms seem to function synergistically and are able to compete for certain ecological niches (Berendsen et al., 2018; Woo and Pepe, 2018). For this reason, the use of complete microbiomes or core microbiomes (both cultivable and non-cultivable strains) could represent a promising alternative to modify the microbial communities native to agroecosystems in order to counteract the negative effects of climate change.

\section{NATURAL MICROBIOME ENGINEERING. THE NEW HORIZONS TO ALLEVIATE CLIMATE CHANGE CONSEQUENCES}

Currently, several studies have been highlighted the important role of root endosphere, which are able to recruit desirable microorganism from soil to improve plant fitness and yields of crops (Kasotia and Choudhary, 2014; Molina-Montenegro et al., 2016; Berg and Koskella, 2018; Durán et al., 2018; Lata et al., 2018; 
TABLE 1 | Plant Growth Promoting Microorganisms isolated from extreme environment to improve crop production.

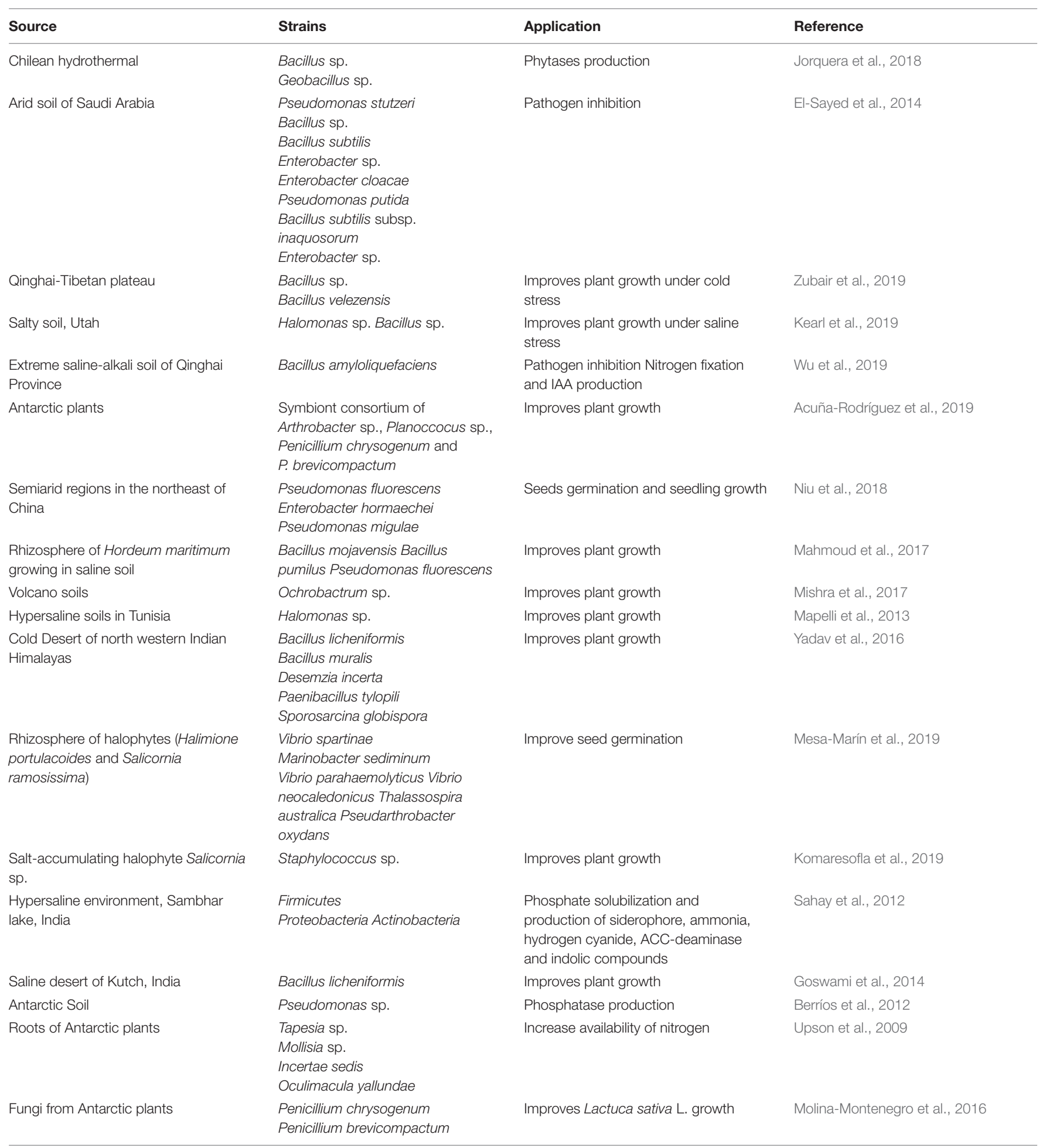

Orozco-Mosqueda et al., 2018; Carrión et al., 2019; Dubey and Sharma, 2019; Harman and Uphoff, 2019). To date, some studies have identified the structure and function of the microbiome in agricultural crops including barley (Bulgarelli et al., 2015), soybean (Mendes et al., 2014; Rascovan et al., 2016), maize (Aira et al., 2010; Gomes et al., 2018), wheat (Donn et al., 2015; Chen et al., 2018) and rice (Edwards et al., 2015). In fact, studies showed that plants can select their microbiome and desirable traits can be transmitted. For example, multigenerational experimental systems with Arabidopsis thaliana have been used to select soil 
microbiomes that induce different flowering times. Microbiome selected from the 10th generation of A. thaliana was inoculated in A. thaliana and Brassica rapa soils and the characteristics were transferred (Panke-Buisse et al., 2015). Thus, plant microbiome is gaining considerable interest since they play an important role in the regulation of plant metabolism (Pieterse et al., 2014; Mueller et al., 2016), where plants can adjust their microbiome and specifically recruit the microorganisms involved in plant fitness with a subsequent assembly of protective specific microbiota, a phenomenon that was recently called "Cry for Help" (Bakker et al., 2018; Berendsen et al., 2018; Li X. et al., 2019; Rolfe et al., 2019). Although this new theory is mainly related to biotic stresses, Liu et al. (2015) showed that the respiratory metabolic capacity of mycorrhizal rice (Oryza sativa) under low-temperature stress accelerated the biosynthesis of strigolactone to recruit AMF (Glomus intraradices). On the other hand, in a study published by Jochum et al. (2019b), it was possible to modify the phenotype of Triticum aestivum subsp. aestivum, using host-mediated microbiome engineering as a strategy to improve the resistance of this crop to drought stress. therefore, this phenomenon could eventually be associated with different abiotic stress such as high radiation, freezing, among others.

The modification of the microbial communities is given by the alteration of the radical exudation profiles of primary and secondary metabolites with biocidal and/or semiochemical activities, which influences the microbiome recruiting specific microorganisms and their microbial activities (Rudrappa et al., 2008; Hassan and Mathesius, 2012; Massalha et al., 2017; Rolfe et al., 2019). This restructuring of microbiome involves the exudation of compounds that could serve as a substrate for microbial growth, elicit chemotactic responses and facilitate root colonization or inhibit the growth of some microbial groups through the release of antimicrobial compounds (Figure 1). Furthermore, exudates can interact with microbial quorum sensing systems causing the release of metabolites derived from microbial metabolism (Rolfe et al., 2019). To date, the secondary metabolites from Shikimate biosynthetic pathway and derivatives of Isopentenodiphosphate (IPP) pathway have been most reported (Rolfe et al., 2019). The concept of cry for help is based on many studies, for example, it has been shown that Arabidopsis plants infected with the foliar pathogen, Pseudomonas syringae, increase the secretion of L-malic acid toward the rhizosphere, selectively recruiting the rhizobacterium Bacillus subtilis promoting the formation of biofilms in the roots and consequently increasing plant defenses (Rudrappa et al., 2008). Some years after, studies conducted by Lakshmanan et al. (2012) demonstrated that foliar infection by Pseudomonas syringae induced the expression of aluminumactivated malate transporter 1 (ALMT1) that increases the expression of L-malic acid toward the rhizosphere which caused a systemic resistance response induced in plants against pathogen by recruiting of $B$. subtilis. In addition, a study by Berendsen et al. (2018) shows that $A$. thaliana recruit three bacterial phylum (Proteobacteria, Firmicutes, and Bacteroidetes) in the rhizosphere after activation of foliar defense by the downy mildew pathogen, Hyaloperonospora arabidopsidis.
Thus, currently it is well known that the survival of plants depends on the interaction with the holobiont. However, the protective function is not carried out by all microorganisms, but rather by some microbial groups that, due to additive or synergistic effects, are fundamental to the functioning of this protection network. These key microorganisms within the microbiome, called "core microbiome", forms strong facultative and mutualistic interactions with the other microorganisms inside the microbiome to generate the protective effect. The core microbiome concept was introduced in human microbiome studies to define a relatively stable community that contributes to important biological functions (Human Microbiome Project Consortium, 2012). The core microbiome are small fractions of OTUs (operational taxonomic units) that represent $<\sim 20 \%$ of the total microbial diversity but that represents more than $\sim 90 \%$ of the relative abundance of bacterial and fungal OTUs assembled in the different organs of the plant, which maintain their high relative abundance during the development of the plant (Lundberg et al., 2012; Armanhi et al., 2016; de Souza et al., 2016; Armanhi et al., 2018; Toju et al., 2018a,b). The importance of the core microbiome has been tested experimentally in recent years, for example, Niu et al. (2017) evaluated the role of a simplified synthetic microbial consortium formed by seven strains of four phyla (E. cloacae, Stenotrophomonas maltophilia, Ochrobactrum pituitosum, Herbaspirillum frisingense, Pseudomonas putida, Curtobacterium pusillum, and Chryseobacterium indologenes) identified by culture-dependent techniques. The authors showed that elimination of $E$. cloacae led to the complete loss of the community, suggesting an important role of the key species in the functioning of the total community. Studies conducted by de Souza et al., 2016 found that a core microbiome composed of $25 \%$ of the total microbial diversity of endophytic microorganisms (bacteria and fungi) and 15\% of exophytic microorganisms, represented more than $90 \%$ of the relative abundance of bacteria and fungi found in the different organs of the sugarcane plant. Therefore, identify, add or modify the core microbiome in different agriculture crops represents a promising alternative to counteract the negative effects of climate change. In fact, strengthening the core microbiome is defined among the five research priorities "For harnessing plant microbiomes in sustainable agriculture" (Busby et al., 2017). From this point of view, different studies showed that the synthetic design and transplantation of core microbiomes can improve plant fitness. For example, Armanhi et al. (2018) identified and isolated the core microbiome from roots and stems of sugarcane and then was inoculated into maize plants. As a result, members of the synthetic community efficiently colonized plants organs, displacing the natural microbiota and dominate at $53.9 \%$ of the rhizosphere microbial abundance generating a 3.4 -fold increase in plant biomass compared to non-inoculated plants. In natural environment, plants have evolved together with their microbiota adapting to local environmental conditions ensuring the survival of the holobiont (Cordovez et al., 2019). However, few studies have attempted to identify these processes in plants of extreme environments. The native plants microbiome 


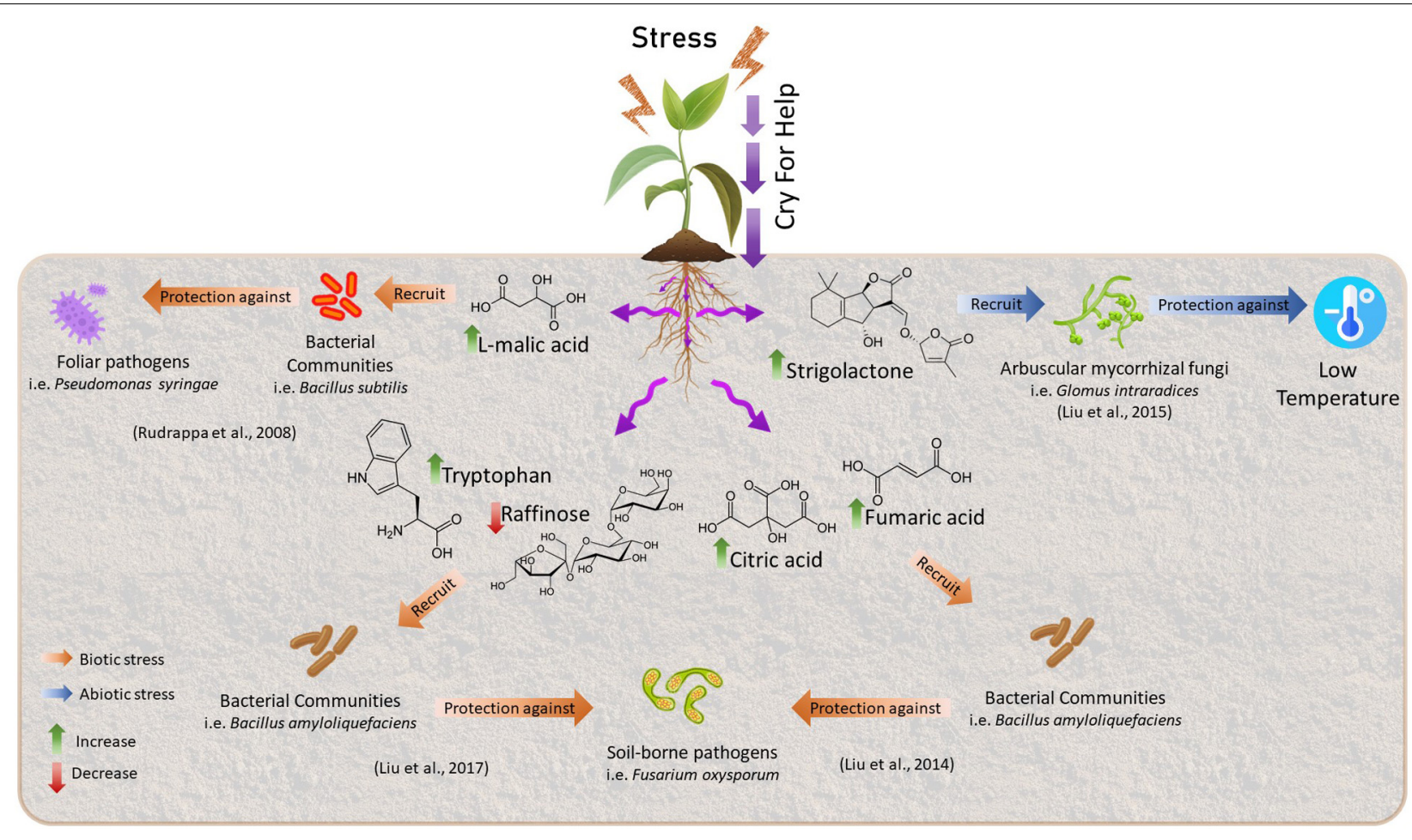

FIGURE 1 | Examples of Cry for help process. Plants undergoing environmental stress could change their radical exudation profiles of primary and secondary metabolites to recruit beneficial microorganisms to counteract the negative effect of the stress.

of extreme environments could represent an unequaled source of stress-ameliorating microorganism and the natural microbiome engineering by using extreme microbiome could represent a promising and eco-friendly alternative to ensure the global food security.

\section{EXTREME MICROBIOME TO THE SERVICE OF SUSTAINABLE AGRICULTURE}

The plant holobiome has been developed over the centuries to adapt to the different terrestrial biomes. Cold environments, such as Antarctic, and dry environments, such as Deserts, have aroused great curiosity regarding the assembly of microbial communities and microbe-plant interactions. Although the study of the microbiome in extreme environments is still an incipient area, some authors have begun to identify the complex interactions between the microbiome and vegetation associated with these hostile environments. For example, desert (also known as dry/arid environments) represent about a third of the planet's biomes, which are characterized by significant absence of rainfall, extreme fluctuations in temperature, generally low nutrient status, high levels of incident UV radiation and strong winds (Chamizo et al., 2012; Stomeo et al., 2013). The microorganisms associated with these environments are generally represented by Bacteria, Fungi, and Archaea (Makhalanyane et al., 2015; Fernández-Martínez et al.,
2019). Bacterial communities present in desert soils typically contain a number of ubiquitous phyla including Actinobacteria, Bacteroidetes and Proteobacteria (Fierer et al., 2009). In the case of fungi, most of the studies have identified phyla that included members of Basidiomycota and Ascomycota, with high taxonomic diversity, both thermophilic and thermotolerant fungi (Fierer et al., 2012; Makhalanyane et al., 2015). Archeal taxa are relatively rare across many environments but seem to be particularly abundant in desert soils, with the Thaumarchaeota phylum the most representative (Fierer et al., 2012; Marusenko et al., 2013). Although we know little about the microbial diversity of desert environments, new metagenomic data have shown functional diversity and a large abundance of genes involved in biogeochemical cycles that, although much less than other terrestrial biomes, could generate functional trophic chains (Makhalanyane et al., 2015).

Some authors have investigated the use of PGPM from these environments, for example, El-Sayed et al., 2014, isolated native bacteria from rhizospheric arid soils and evaluated both growth-promoting capabilities and antagonistic potential against fungi and phytopathogenic nematodes. They found bacteria that exhibited capacities to fix atmospheric nitrogen, produce ammonia, indole-3-acetic acid (IAA), siderophores, solubilize phosphate and zinc, and showed a potential antagonist against some phytopathogenic fungi and a species of nematodes (Meloidogyne incognita) to varying degrees. Moreover, Niu et al., 2017 identified bacterial strains of foxtail millet (Setaria italica L.), a drought-tolerant crop 


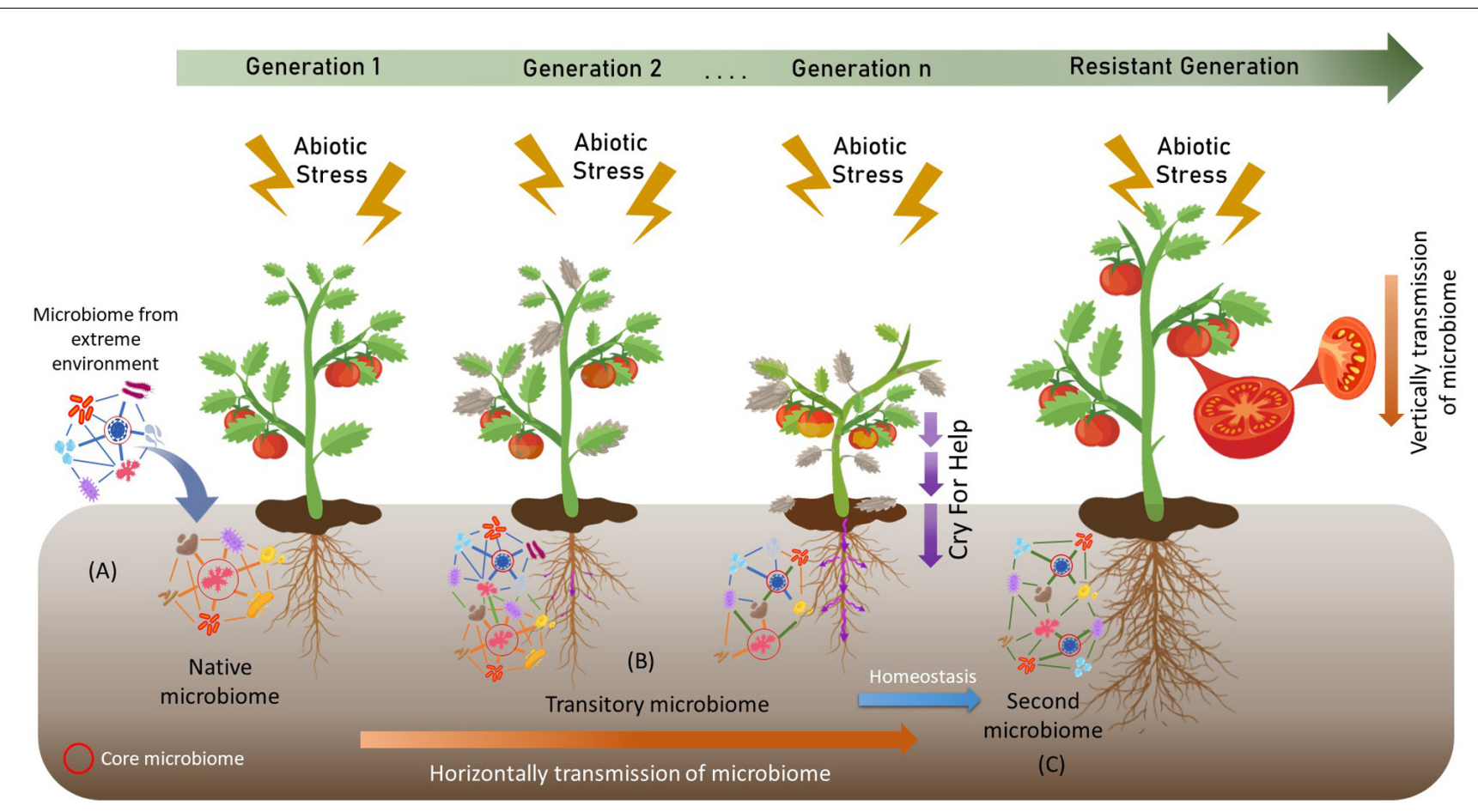

FIGURE 2 | Artificial selection of microbiomes by host-mediated and multigenerational selection. (A) The incorporation of an extreme microbiome modifies the native microbiome. (B) This new transitory microbiome is transmitted horizontally through the soil and undergoes alterations through the processes of Cry For Help. (C) After time, the microbiome reach homeostasis forming a second microbiome that helps to alleviate the negative effects of climate change.

grown in semi-arid regions in northeast China. They observed that four isolated strains had the ability to generate ACC deaminase, as well as tolerance to drought. In the case of microbiome, some plant-associated microbiomes have been identified in deserts habitats, for example, Coleman-Derr et al. (2016) identified microbiomes of three Agave species (Agave tequilana FAC Weber, Salmian Agave Otto ex Salm subsp. crassispina (Trel.) Gentry, and Agave deserti Engelm) distributed in central Mexico and in southern California, finding microorganisms capable of conferring resistance to high temperatures and low water availability. Moreover, FonsecaGarcía et al. (2016) identified the holobioma of succulent plants (Family Cactaceae) native to arid and semi-arid ecosystems which also are represent microorganisms capable of conferring drought resistance.

Other desert environments such as the Atacama Desert in Chile, have aroused great scientific interest in recent years. This desert, considered the driest in the world, has a great microbial diversity that is still largely unknown taxonomically (Bull et al., 2016). Recently, some studies have investigated in the microbiome dynamics associated with the "Atacama Flowering Events," which corresponds to an explosive bloom of dormant desert plants produced by the presence of water as precipitation (Vidiella et al., 1999). Studying this phenomenon, it was discovered that some bacterial groups and their activity can influence the growth and flowering of native plants (Araya et al., 2020; Astorga-Eló et al., 2020). Similarly, cold desert such as Antarctic have also been studied. The Antarctic pristine environment is the most extreme land on the planet and represents an interesting and unique habitat for the colonization and survival of microbial life. The first expeditions and studies in Antarctica suggested that this territory as sterile and with limited microbial activity (Cameron et al., 1968). However, in the recent years a large number of studies have demonstrated a high diversity of microorganisms with structured trophic chains that form functional microbial communities (Cary et al., 2010; Teixeira et al., 2013; Niederberger et al., 2015, 2019; Jorquera et al., 2016; Pudasaini et al., 2017; Durán et al., 2019). Over the years, a number of particular characteristics of Antarctic environment have been discussed and investigated. The combination of an extensive glacial layer, intense katabatic winds, high radiation and extremely low precipitation rates (low 2\%) makes them the oldest, cold, dry and hostile territory for microorganisms. This environment is dominated by strong gradients in temperature, salinity (35-150\%), and irradiation ( $<0.1 \%$ to $1-5 \%$ UV radiation), properties highly variable and ultimately governed by air temperature and snow cover. This strong selective pressure leads to the evolution of novel mechanisms for stress tolerance by indigenous microorganisms, forming an important ecological niche. The extreme environmental conditions of Antarctica greatly limit the establishment of plants. However, the Maritime Antarctic region (mainly in the Antarctic Peninsula) provides favorable weather conditions for the establishment of the only two vascular plants: Deschampsia antarctica and Colobanthus quitensis (Alberdi et al., 2002). 
To date, some studies have identified the role that extreme microorganisms play in the nutrition and survival of these vascular plants. For example, Antarctic Pseudomonas were characterized that help solubilize phosphate sources to enhance phosphorus absorption by D. antarctica (Berríos et al., 2012; Yarzábal et al., 2018). In the case of fungi, studies have mainly focused on endophytic fungi. For example, fungi with dematiaceous septate hyphae (Dark Septate Endophytes) capable of mineralizing peptides and amino acids have been found in the rhizosphere of $D$. antarctica, indicating that they increase the availability of nitrogen for the plant (Upson et al., 2009). Moreover, endophytic symbiont yeasts (Cryptococcus victoriae, Cystobasidium laryngis, Rhodotorula mucilaginosa, Sporidiobolus ruineniae, and Leucosporidium aff. golubevii) have been identified in leaves of both vascular plants that could directly or indirectly promote the fitness of host plants (Santiago et al., 2017). Recently, studies by Ramos et al. (2018) demonstrate that endophytic fungi present in $C$. quitensis modulate the content of salicylic acid, jasmonate, indole-3-acetate and ABA in shoot tissue of plants exposed to UV-B radiation, which would indicate that these endophytic fungi could modulate the hormonal content of C. quitensis to improve its ecophysiological performance under high UV-B radiation. Thus, the plant-associated microorganisms can play a crucial role to ensure the plant survival (Upson et al., 2009; Torres-Díaz et al., 2016; Gallardo-Cerda et al., 2018; Ramos et al., 2018; Ballesteros et al., 2020).

Nowadays, the use of Antarctic microorganisms to enhance the yield of agricultural crops under this new scenario of climate change is more frequent. In the case of Emerging Infectious Disease, Melo et al. (2016) isolated epiphytic bacteria from D. antarctica that inhibit Botrytis cinerea, and Javeria et al. (2014) showed that lichen forming fungi isolated from Everniastrum cirrhatum lichen have important antimicrobial properties against Fusarium moniliforme, Fusarium oxysporum and Fusarium udum. On the other hand, Molina-Montenegro et al. (2016), show the potential of some Antarctic endophytic fungi isolated from $C$. quitensis and $D$. antarctica to improve the net photosynthetic rate and water absorption under drought conditions in cultivars of Lactuca sativa L. var. Longifolia. In addition, a recent study conducted by Acuña-Rodríguez et al. (2019) formulated a consortium of microorganisms formed by two growth-promoting rhizobacteria of the genus Arthrobacter and Planoccocus and two endophytic root fungi Penicillium chrysogenum and Penicillium brevicompactum that worked effectively to reduce saline stress in pepper, lettuce, onion and tomato plants. The results of these experiments demonstrate a high capacity to enhance crop yield under biotic and abiotic stresses by some microorganisms. However, as discussed earlier, the use of few microorganisms generally represents low success in the field due to the low adaptability and competition of introduced microorganisms with the native microorganisms.

A recent study by Molina-Montenegro et al. (2019) suggests that D. antarctica and C. quitensis can modify their rhizosphere microbiome under different stress conditions. Similarly, Citlali et al. (2018) suggest that the rhizosphere and phyllosphere of CAM plants differentially benefit their host plants to succeed in drylands. The transfer of microbiomes or core microbiomes could mitigate the negative effects of different biotic and abiotic stresses on agricultural crops. However, as far as we know, the use of microbiomes or core microbiomes from this hostile environment to improve the resistance of agricultural crops has not been investigated. Different studies have shown that it is possible to transfer complete microbiomes by transplants of small portions of soil (Lau and Lennon, 2012; PankeBuisse et al., 2015; Tkacz et al., 2015; Yergeau et al., 2015; Calderón et al., 2017; Howard et al., 2017). For example, Howard et al. (2017) demonstrated a successful transfer of soil microbiomes from an urban forest in Ithaca, NY, United States. After 3 weeks of incubation, the pots with $5 \% \mathrm{v} / \mathrm{v}$ soil presented a similar composition of microbial communities to the transferred soil. In addition, as we have already discussed, microbiomes are capable of modifying the metabolism and phenological stages of some plants. Therefore, the combination of extreme microbiomes, together with processes such as cry for help, where the plant recruits the microorganisms it needs to resist stresses, could generate new and naturally selected entities that help crops withstand these unfavorable conditions (Figure 2). The identification of these new central entities through the new "meta-omics" techniques could enhance knowledge about the dynamics of microbial communities in specific situations in order to perform more precise and more resilient bioinoculants in the soil.

\section{IMPACT OF THE APPLICATION OF MICROBIOMES IN SOILS}

In the soil, the microbial communities are responsible for nutrient cycling, absorption and release of nutrients, mineralization and processing of organic and inorganic compounds (Madsen, 2011; Falkowski et al., 2012; Jansson and Hofmockel, 2019). These processes are highly dynamic and depend largely on environmental conditions, but also on the interactions between the biotic components of the system (Churchland and Grayston, 2014). The microbe-microbe and microbe-plant interaction is essential for the proper functioning of the biogeochemical cycles. Some studies indicate that the introduction of microorganisms can positively influence native microbial communities and soils processes (Miethling et al., 2000; Johansen and Binnerup, 2006; Singh et al., 2010; CastroSowinski et al., 2007; Bargaz et al., 2018). For example, the inoculation of with Azospirillum sp. improves the efficiency of nitrogen absorption in soil, influencing the metabolic activity of other microbial communities (Salamone et al., 2010, 2012). Besides, the inoculation of Azospirillum sp. and Pseudomonas sp. can increase in the diversity of microbial communities in wheat crops, which produces large changes in profiles of carbon-source utilization modifying the soil carbon pools, generating labile organic matter and increasing soil fertility (Naiman et al., 2009).

In the case of complete microbiomes, the information is limited and even more in terms of agroecosystems. Some studies have begun to analyze the effect of microbiome transferring in different scenarios. For example, Zhao et al. (2014) used 
soil transplants, and consequently their microbiomes, in order to study changes in soil biogeochemical cycles. They showed that after 4 years of soil transplantation, microbial functional diversity and the processes involved in the nitrogen cycle increased considerably. Surprisingly, genes associated with the nitrogen and carbon processing increased in abundance, coinciding with a greater potential for soil nitrification and carbon sequestration. On the other hand, Yergeau et al. (2015) showed that the microbiome transferring helps the growth of willows on petroleum-contaminated soils. However, after 100 days of incorporation of the microbiome, the microbial communities tend to be similar to the original maintaining the resistance of the willow. The authors suggest that the willow rapidly exerts strong selective pressures in the rhizosphere, selecting for a similar microbiome from starting microbiomes. Recently, Chaudhary et al. (2019) showed that indigenous soil microbial community structure was not disturbed by the external application of exogenous microorganisms, despite their were able to improve plant growth promoting traits (i.e., nutrients availability, phosphatase activity). Therefore, the incorporation of exogenous microbiomes or beneficiary microorganisms does not perturb the natural soil microbial community.

\section{CONCLUDING REMARKS AND FUTURE PROSPECTIVE}

The new metaomics techniques have significantly increased our knowledge about the dynamics and abundance of microbial communities in soil-plant systems. However, the complex interactions between microorganisms-plants-soil is largely unknown. In the current scenario of climate change, a new green revolution is required to achieve future food security, with

\section{REFERENCES}

Abe, H., Yamaguchi-Shinozaki, K., Urao, T., Iwasaki, T., Hosokawa, D., and Shinozaki, K. (1997). Role of Arabidopsis MYC and MYB homologs in droughtand abscisic acid-regulated gene expression. Plant Cell 9, 1859-1868. doi: 10. 1105/tpc.9.10.1859

Acuña-Rodríguez, I. S., Hansen, H., Gallardo-Cerda, J., Atala, C., and Molina-Montenegro, M. A. (2019). Antarctic extremophiles: biotechnological alternative to crop productivity in saline soils. Front. Bioeng. Biotechnol. 7:22. doi: 10.3389/fbioe.2019.00022

Adesemoye, A. O., Torbert, H. A., and Kloepper, J. W. (2008). Enhanced plant nutrient use efficiency with PGPR and AMF in an integrated nutrient management system. Can. J. Microbiol. 54, 876-886. doi: 10.1139/W08-081

Aira, M., Gómez-Brandón, M., Lazcano, C., Bååth, E., and Domínguez, J. (2010). Plant genotype strongly modifies the structure and growth of maize rhizosphere microbial communities. Soil Biol. Biochem. 42, 2276-2281. doi: 10.1016/j. soilbio.2010.08.029

Alabouvette, C., Olivain, C., Migheli, Q., and Steinberg, C. (2009). Microbiological control of soil-borne phytopathogenic fungi with special emphasis on wiltinducing Fusarium oxysporum. New Phytol. 184, 529-544. doi: 10.1111/j.14698137.2009.03014.x

Alberdi, M., Bravo, L. A., Gutiérrez, A., Gidekel, M., and Corcuera, L. J. (2002). Ecophysiology of Antarctic vascular plants. Physiol. Plant. 115, 479-486. doi: 10.1034/j.1399-3054.2002.1150401.x

Alexieva, V., Sergiev, I., Mapelli, S., and Karanov, E. (2001). The effect of drought and ultraviolet radiation on growth and stress markers in pea and new concepts and approaches to achieve a more sustainable development of agriculture. In this context, the study and use of complete microbiomes or core microbiomes from extreme environments could represent a promising alternative to increase crop yields under different stress conditions. These microorganisms could transfer their innate resistance to agricultural crops. Furthermore, news formulations of bioinoculants composed of microbiomes or core microbiomes could eliminate the ecological barriers imposed by native microbial communities in soil, increasing the persistence of added microorganisms. In addition, the formulation of bioinoculants from the natural selection imposed by plants, through the phenomenon of cry for help, where the plant in stress situations selects its microbiome represents an ecofriendly alternative for a new generation of bioinoculants taking advantage of the closed relationship between the microbiome and their hosts, which could represent an excellent alternative to improve the plant fitness to counteract the climate change effects.

\section{AUTHOR CONTRIBUTIONS}

$\mathrm{RR}$ wrote the main manuscript text. PD critically revised the manuscript and approved the final version.

\section{FUNDING}

This study was supported by the Instituto Antártico Chileno (INACH), Regular project RT_06-17 from the Chilean government, Agencia Nacional de Investigación y Desarrollo ANID-FONDECYT regular project No. 1201196 and RR Ph.D. grant ANID-No. 21180649.

wheat. Plant Cell Environ. 24, 1337-1344. doi: 10.1046/j.1365-3040.2001.0 0778.x

Ammar, M. H., Anwar, F., El-Harty, E. H., Migdadi, H. M., Abdel-Khalik, S. M., AlFaifi, S. A., et al. (2015). Physiological and yield responses of faba bean (Vicia faba L.) to drought stress in managed and open field environments. J. Agron. Crop Sci. 201, 280-287. doi: 10.1111/jac.12112

Araya, J. P., González, M., Cardinale, M., Schnell, S., and Stoll, A. (2020). Microbiome dynamics associated with the atacama flowering desert. Front. Microbiol. 10:3160. doi: 10.3389/fmicb.2019.03160

Armanhi, J. S. L., De Souza, R. S. C., De Araújo, L. M., Okura, V. K., Mieczkowski, P., Imperial, J., et al. (2016). Multiplex amplicon sequencing for microbe identification in community-based culture collections. Sci. Rep. 6, 1-9. doi: $10.1038 /$ srep 29543

Armanhi, J. S. L., de Souza, R. S. C., de Damasceno, N. B., de Araújo, L. M., Imperial, J., and Arruda, P. (2018). A community-based culture collection for targeting novel plant growth-promoting bacteria from the sugarcane microbiome. Front. Plant Sci. 8:2191. doi: 10.3389/fpls.2017. 02191

Astorga-Eló, M., Zhang, Q., Larama, G., Stoll, A., Quecine, M. C., and Charles, T. C. (2020). Composition, predicted functions and co-occurrence networks of rhizobacterial communities impacting flowering desert events in the Atacama Desert, Chile. Front. Microbiol. 11:571. doi: 10.3389/fmicb.2020. 00571

Bahadur, A., Batool, A., Nasir, F., Jiang, S., Mingsen, Q., Zhang, Q., et al. (2019). Mechanistic insights into arbuscular mycorrhizal fungi-mediated drought stress tolerance in plants. Int. J. Mol. Sci. 20, 1-18. doi: 10.3390/ijms20174199 
Bais, A. F., McKenzie, R. L., Bernhard, G., Aucamp, P. J., Ilyas, M., Madronich, S., et al. (2015). Ozone depletion and climate change: impacts on UV radiation. Photochem. Photobiol. Sci. 14, 19-52. doi: 10.1039/c4pp90032d

Bakker, P. A. H. M., Pieterse, C. M. J., de Jonge, R., and Berendsen, R. L. (2018). The soil-borne legacy. Cell 172, 1178-1180. doi: 10.1016/j.cell.2018. 02.024

Ballesteros, G. I., Torres-Díaz, C., Bravo, L. A., Balboa, K., Caruso, C., Bertini, L., et al. (2020). In silico analysis of metatranscriptomic data from the Antarctic vascular plant Colobanthus quitensis: responses to a global warming scenario through changes in fungal gene expression levels. Fung. Ecol. 43:100873. doi: 10.1016/j.funeco.2019.100873

Bargaz, A., Lyamlouli, K., Chtouki, M., Zeroual, Y., and Dhiba, D. (2018). Soil microbial resources for improving fertilizers efficiency in an integrated plant nutrient management system. Front. Microbiol. 9:1606. doi: 10.3389/fmicb. 2018.01606

Barra, P. J., Pontigo, S., Delgado, M., Parra-Almuna, L., Duran, P., Valentine, A. J., et al. (2019). Phosphobacteria inoculation enhances the benefit of P-fertilization on Lolium perenne in soils contrasting in P-availability. Soil Biol. Biochem. 136:107516. doi: 10.1016/j.soilbio.2019.06.012

Barra, Patricio, J., Inostroza, N. G., Acuña, J. J., Mora, M. L., Crowley, D. E., et al. (2016). Formulation of bacterial consortia from avocado (Persea americana Mill.) and their effect on growth, biomass and superoxide dismutase activity of wheat seedlings under salt stress. Appl. Soil Ecol. 102, 80-91. doi: 10.1016/j. apsoil.2016.02.014

Basahi, J. M., Ismail, I. M., and Hassan, I. A. (2014). Effects of enhanced UV-B radiation and drought stress on photosynthetic performance of lettuce (Lactuca sativa L. romaine) plants. Annu. Res. Rev. Biol. 4, 1739-1756. doi: 10.9734/arrb/ 2014/6638

Berendsen, R. L., Vismans, G., Yu, K., Song, Y., De Jonge, R., Burgman, W. P., et al. (2018). Disease-induced assemblage of a plant-beneficial bacterial consortium. ISME J. 12, 1496-1507. doi: 10.1038/s41396-018-0093-1

Berg, M., and Koskella, B. (2018). Nutrient- and dose-dependent microbiomemediated protection against a plant pathogen. Curr. Biol. 28, 2487.e3-2492.e3. doi: 10.1016/j.cub.2018.05.085

Bernardo, L., Carletti, P., Badeck, F. W., Rizza, F., Morcia, C., Ghizzoni, R., et al. (2019). Metabolomic responses triggered by arbuscular mycorrhiza enhance tolerance to water stress in wheat cultivars. Plant Physiol. Biochem. 137, 203212. doi: 10.1016/j.plaphy.2019.02.007

Berríos, G., Cabrera, G., Gidekel, M., and Gutiérrez-Moraga, A. (2012). Characterization of a novel antarctic plant growth-promoting bacterial strain and its interaction with antarctic hair grass (Deschampsia antarctica Desv). Polar Biol. 36, 349-362. doi: 10.1007/s00300-012-1264-6

Borody, T. J., and Khoruts, A. (2012). Fecal microbiota transplantation and emerging applications. Nat. Rev. Gastroenterol. Hepatol. 9, 88-96. doi: 10.1038/ nrgastro.2011.244

Bulgarelli, D., Garrido-Oter, R., Münch, P. C., Weiman, A., Dröge, J., Pan, Y., et al. (2015). Structure and function of the bacterial root microbiota in wild and domesticated barley. Cell Host Microbe 17, 392-403. doi: 10.1016/j.chom. 2015.01.011

Bull, A. T., Asenjo, J. A., Goodfellow, M., and Gómez-Silva, B. (2016). The atacama desert: technical resources and the growing importance of novel microbial diversity. Annu. Rev. Microbiol. 70, 215-234. doi: 10.1146/annurev-micro102215-095236

Busby, P. E., Soman, C., Dangl, J. L., Bennett, A., Morsy, M., Friesen, M. L., et al. (2017). Research priorities for harnessing plant microbiomes in sustainable agriculture. PLoS Biol. 15:e2001793. doi: 10.1371/journal.pbio. 2001793

Calderón, K., Spor, A., Breuil, M. C., Bru, D., Bizouard, F., Violle, C., et al. (2017). Effectiveness of ecological rescue for altered soil microbial communities and functions. ISME J. 11, 272-283. doi: 10.1038/ismej.2016.86

Calvo-Polanco, M., Sánchez-Romera, B., Aroca, R., Asins, M. J., Declerck, S., Dodd, I. C., et al. (2016). Exploring the use of recombinant inbred lines in combination with beneficial microbial inoculants (AM fungus and PGPR) to improve drought stress tolerance in tomato. Environ. Exp. Bot. 131, 47-57. doi: 10.1016/j.envexpbot.2016.06.015

Cameron, R. E., King, J., and David, C. N. (1968). Soil microbial and ecological studies in southern Victoria Land. Antarctic J. U.S. 11, 121-123.

Carrión, V. J., Perez-Jaramillo, J., Cordovez, V., Tracanna, V., de Hollander, M., Ruiz-Buck, D., et al. (2019). Pathogen-induced activation of disease-suppressive functions in the endophytic root microbiome. Science 366, 606-612. doi: 10. 1126/science.aaw9285

Cary, S. C., McDonald, I. R., Barrett, J. E., and Cowan, D. A. (2010). On the rocks: the microbiology of Antarctic dry valley soils. Nat. Rev. Microbiol. 8, 129-138. doi: $10.1038 /$ nrmicro2281

Castro-Sowinski, S., Herschkovitz, Y., Okon, Y., and Jurkevitch, E. (2007). Effects of inoculation with plant growth-promoting rhizobacteria on resident rhizosphere microorganisms. FEMS Microbiol. Lett. 276, 1-11. doi: 10.1111/j. 1574-6968.2007.00878.x

Cavicchioli, R., Ripple, W. J., Timmis, K. N., Azam, F., Bakken, L. R., Baylis, M., et al. (2019). Scientists' warning to humanity: microorganisms and climate change. Nat. Rev. Microbiol. 17, 569-586. doi: 10.1038/s41579-019-0222-5

Challinor, A. J., Watson, J., Lobell, D. B., Howden, S. M., Smith, D. R., and Chhetri, N. (2014). A meta-analysis of crop yield under climate change and adaptation. Nat. Clim. Change 4, 287-291. doi: 10.1038/nclimate2153

Chamizo, S., Cantón, Y., Lázaro, R., Solé-Benet, A., and Domingo, F. (2012). Crust composition and disturbance drive infiltration through biological soil crusts in semiarid ecosystems. Ecosystems 15, 148-161. doi: 10.1007/s10021-011-9499-6

Chaudhary, D. R., Rathore, A. P., and Sharma, S. (2019). Effect of halotolerant plant growth promoting rhizobacteria inoculation on soil microbial community structure and nutrients. Appl. Soil Ecol. 150:103461. doi: 10.1016/j.apsoil.2019. 103461

Chen, Y., Wang, J., Yang, N., Wen, Z., Sun, X., Chai, Y., et al. (2018). Wheat microbiome bacteria can reduce virulence of a plant pathogenic fungus by altering histone acetylation. Nat. Commun. 9, 1-14. doi: 10.1038/s41467-01805683-7

Churchland, C., and Grayston, S. J. (2014). Specificity of plant-microbe interactions in the tree mycorrhizosphere biome and consequences for soil C cycling. Front. Microbiol. 5:261. doi: 10.3389/fmicb.2014.00261

Citlali, F.-G., Desgarennes, D., Flores-Núñez, V. M., and Partida-Martínez, L. P. (2018). Chapter 12 - The microbiome of desert cam plants: lessons from amplicon sequencing and metagenomics. Metagenomics 2018, 231-254. doi: 10.1016/B978-0-08-102268-9.00012-4

Coffey, A., Prinsen, E., Jansen, M. A. K., and Conway, J. (2017). The UVB photoreceptor UVR8 mediates accumulation of UV-absorbing pigments, but not changes in plant morphology, under outdoor conditions. Plant Cell Environ. 40, 2250-2260. doi: 10.1111/pce.13025

Coleman-Derr, D., Desgarennes, D., Fonseca-Garcia, C., Gross, S., Clingenpeel, S., Woyke, T., et al. (2016). Plant compartment and biogeography affect microbiome composition in cultivated and native Agave species. New Phytol. 209, 798-811. doi: 10.1111/nph.13697

Cordovez, V., Dini-Andreote, F., Carrión, V. J., and Raaijmakers, J. M. (2019). Ecology and evolution of plant microbiomes. Annu. Rev. Microbiol. 73, 69-88. doi: 10.1146/annurev-micro-090817-062524

Cutler, S. R., Rodriguez, P. L., Finkelstein, R. R., and Abrams, S. R. (2010). Abscisic acid: emergence of a core signaling network. Annu. Rev. Plant Biol. 61, 651-679. doi: 10.1146/annurev-arplant-042809-112122

de Souza, R. S. C., Okura, V. K., Armanhi, J. S. L., Jorrín, B., Lozano, N., Da Silva, M. J., et al. (2016). Unlocking the bacterial and fungal communities assemblages of sugarcane microbiome. Sci. Rep. 6, 1-15. doi: 10.1038/srep28774

Donn, S., Kirkegaard, J. A., Perera, G., Richardson, A. E., and Watt, M. (2015). Evolution of bacterial communities in the wheat crop rhizosphere. Environ. Microbiol. 17, 610-621. doi: 10.1111/1462-2920.12452

Dresselhaus, T., and Hückelhoven, R. (2018). Biotic and abiotic stress responses in crop plants. Agronomy 8:267. doi: 10.3390/agronomy8110267

Dubey, S., and Sharma, S. (2019). "Rhizospheric microbiome engineering as a sustainable tool in agriculture: approaches and challenges," in Microbial Diversity in Ecosystem Sustainability and Biotechnological Applications, eds T. Satyanarayana, S. Das, and B. Johri (Singapore: Springer).

Durán, P., Barra, P. J., Jorquera, M. A., Viscardi, S., Fernandez, C., Paz, C., et al. (2019). Occurrence of soil fungi in antarctic pristine environments. Front. Bioeng. Biotechnol. 7:28. doi: 10.3389/fbioe.2019.00028

Durán, P., Thiergart, T., Garrido-Oter, R., Agler, M., Kemen, E., Schulze-Lefert, P., et al. (2018). Microbial interkingdom interactions in roots promote Arabidopsis survival. Cell 175, 973.e14-983.e14. doi: 10.1016/j.cell.2018.10.020

Edwards, J., Johnson, C., Santos-Medellín, C., Lurie, E., Podishetty, N. K., Bhatnagar, S., et al. (2015). Structure, variation, and assembly of the rootassociated microbiomes of rice. Proc. Natl. Acad. Sci. U.S.A. 112, E911-E920. doi: $10.1073 /$ pnas. 1414592112 
El-Sayed, W. S., Akhkha, A., El-Naggar, M. Y., and Elbadry, M. (2014). In vitro antagonistic activity, plant growth promoting traits and phylogenetic affiliation of rhizobacteria associated with wild plants grown in arid soil. Front. Microbiol. 5:651. doi: 10.3389/fmicb.2014.00651

Esposito, A., Colantuono, C., Ruggieri, V., and Chiusano, M. L. (2016). Bioinformatics for agriculture in the next-generation sequencing era. Chem. Biol. Technol. Agric. 3, 1-12. doi: 10.1186/s40538-016-0054-8

Etesami, H., and Maheshwari, D. K. (2018). Use of plant growth promoting rhizobacteria (PGPRs) with multiple plant growth promoting traits in stress agriculture: action mechanisms and future prospects. Ecotoxicol. Environ. Saf. 156, 225-246. doi: 10.1016/j.ecoenv.2018.03.013

Falkowski, P. G., Fenchel, T., and Delong, E. F. (2012). The microbial engines that drive Earth's Biogeochemical Cycles. Science 320, 1034-1039. doi: 10.1126/ science. 1153213

FAO (2016a). Damage and Losses from Climate-Related Disasters in Agricultural Sectors. Rome: FAO.

FAO (2016b). Natural Disasters and Agriculture. Rome: FAO.

Felici, C., Vettori, L., Giraldi, E., Forino, L. M. C., Toffanin, A., Tagliasacchi, A. M., et al. (2008). Single and co-inoculation of Bacillus subtilis and Azospirillum brasilense on Lycopersicon esculentum: effects on plant growth and rhizosphere microbial community. Appl. Soil Ecol. 40, 260-270. doi: 10.1016/j.apsoil.2008. 05.002

Fernández-Martínez, M. Á, dos Santos Severino, R., Moreno-Paz, M., GallardoCarreño, I., Blanco, Y., Warren-Rhodes, K., et al. (2019). Prokaryotic community structure and metabolisms in shallow subsurface of atacama desert playas and alluvial fans after heavy rains: repairing and preparing for next dry period. Front. Microbiol. 10:1641. doi: 10.3389/fmicb.2019.01641

Fierer, N., Leff, J. W., Adams, B. J., Nielsen, U. N., Bates, S. T., Lauber, C. L., et al. (2012). Cross-biome metagenomic analyses of soil microbial communities and their functional attributes. Proc. Natl. Acad. Sci. U.S.A. 109, 21390-21395. doi: $10.1073 /$ pnas. 1215210110

Fierer, N., Strickland, M. S., Liptzin, D., Bradford, M. A., and Cleveland, C. C. (2009). Global patterns in belowground communities. Ecol. Lett. 12, 1238-1249. doi: 10.1111/j.1461-0248.2009.01360.x

Foo, J. L., Ling, H., Lee, Y. S., and Chang, M. W. (2017). Microbiome engineering: current applications and its future. Biotech. J. 12, 1-11. doi: 10.1002/biot. 201600099

Fonseca-García, C., Coleman-Derr, D., Garrido, E., Visel, A., Tringe, S. G., and Partida-Martínez, L. P. (2016). The Cacti microbiome: interplay between habitat-filtering and host-specificity. Front. Microbiol. 7:150. doi: 10.3389/ fmicb.2016.00150

Gallardo-Cerda, J., Levihuan, J., Lavín, P., Oses, R., Atala, C., Torres-Díaz, C., et al. (2018). Antarctic rhizobacteria improve salt tolerance and physiological performance of the Antarctic vascular plants. Polar Biol. 41, 1973-1982. doi: 10.1007/s00300-018-2336-z

Gomes, E. A., Lana, U. G. P., Quensen, J. F., De Sousa, S. M., Oliveira, C. A., Guo, J., et al. (2018). Root-associated microbiome of maize genotypes with contrasting phosphorus use efficiency. Phytobiomes J. 2, 129-137. doi: 10.1094/PBIOMES03-18-0012-R

González-Villagra, J., Marjorie, R.-D., Alberdi, M., Acevedo, P., Loyola, R., Tighe-Neira, R., et al. (2020). Solar UV irradiation effects on photosynthetic performance, biochemical markers, and gene expression in highbush blueberry (Vaccinium corymbosum L.) cultivars. Sci. Hortic. 259:108816. doi: 10.1016/j. scienta.2019.108816

Goswami, D., Dhandhukia, P., Patel, P., and Thakker, J. N. (2014). Screening of PGPR from saline desert of kutch: growth promotion in Arachis hypogea by Bacillus licheniformis A2. Microbiol. Res. 169, 66-75. doi: 10.1016/j.micres.2013. 07.004

Harman, G. E., and Uphoff, N. (2019). Symbiotic root-endophytic soil microbes improve crop productivity and provide environmental benefits. Scientifica 2019:9106395. doi: 10.1155/2019/9106395

Hassan, S., and Mathesius, U. (2012). The role of flavonoids in rootrhizosphere signalling: opportunities and challenges for improving plantmicrobe interactions. J. Exp. Bot. 63, 3429-3444. doi: 10.1093/jxb/err430

Howard, M. M., Bell, T. H., and Kao-Kniffin, J. (2017). Soil microbiome transfer method affects microbiome composition, including dominant microorganisms, in a novel environment. FEMS Microbiol. Lett. 364, 1-8. doi: 10.1093/femsle/ fnx092
Huang, Y. M., Zou, Y. N., and Wu, Q. S. (2017). Alleviation of drought stress by mycorrhizas is related to increased root $\mathrm{H} 2 \mathrm{O} 2$ efflux in trifoliate orange. Sci. Rep. 7, 1-9. doi: 10.1038/srep42335

Human Microbiome Project Consortium. (2012). Structure, function and diversity of the healthy human microbiome. Nature 7402, 207-214. doi: 10.1038/ nature11234

Hunter, M. C., Smith, R. G., Schipanski, M. E., Atwood, L. W., and Mortensen, D. A. (2017). Agriculture in 2050: recalibrating targets for sustainable intensification. BioScience 67, 386-391. doi: 10.1093/biosci/bix010

Huong, N. T. L., Bo, Y. S., and Fahad, S. (2018). Economic impact of climate change on agriculture using ricardian approach: a case of northwest vietnam. J. Saudi Soc. Agric. Sci. 18, 449-457. doi: 10.1016/j.jssas.2018.02.006

Hussain, H. A., Hussain, S., Khaliq, A., Ashraf, U., Anjum, S. A., Men, S., et al. (2018). Chilling and drought stresses in crop plants: implications, cross talk, and potential management opportunities. Front. Plant Sci. 9:393. doi: 10.3389/ fpls.2018.00393

Hussain, S. S. (2019). "Microbe-mediated tolerance in plants against biotic and abiotic stresses," in Microbial Interventions in Agriculture and Environment, eds D. Singh, V. Gupta, and R. Prabha (Singapore: Springer).

Inostroza-Blancheteau, C., Reyes-Díaz, M., Arellano, A., Latsague, M., Acevedo, P., Loyola, R., et al. (2014). Effects of UV-B radiation on anatomical characteristics, phenolic compounds and gene expression of the phenylpropanoid pathway in highbush blueberry leaves. Plant Physiol. Biochem. 85, 85-95. doi: 10.1016/j. plaphy.2014.10.015

Jacobs, J. L., Carroll, T. L., and Sundin, G. W. (2005). The role of pigmentation, ultraviolet radiation tolerance, and leaf colonization strategies in the epiphytic survival of phyllosphere bacteria. Microb. Ecol. 49, 104-113. doi: 10.1007/ s00248-003-1061-4

Jacobs, J. L., and Sundin, G. W. (2001). Effect of solar UV-B radiation on a phyllosphere bacterial community. Appl. Environ. Microbiol. 67, 5488-5496. doi: 10.1128/AEM.67.12.5488-5496.2001

Jangid, K. K., and Dwivedi, P. (2016). Physiological responses of drought stress in tomato: a review. Int. J. Agric. Environ. Biotechnol. 9, 53-61.

Jansson, J. K., and Hofmockel, K. S. (2019). Soil microbiomes and climate change. Nat. Rev. Microbiol. 18, 35-46. doi: 10.1038/s41579-0190265-7

Javeria, S., Shahi, S. K., Shahi, M. P., and Yadava, Y. K. (2014). Isolation of lichen forming fungus of Everniastrum cirrhatum and evaluate its antagonistic and antimicrobial activity. Am. J. Ethnomed. 1, 361-367.

Jochum, M. D., McWilliams, K. L., Borrego, E. J., Kolomiets, M. V., Niu, G., Pierson, E. A., et al. (2019a). Bioprospecting plant growth-promoting rhizobacteria that mitigate drought stress in grasses. Front. Microbiol. 10:2106. doi: 10.3389/fmicb.2019.02106

Jochum, M. D., McWilliams, K. L., Pierson, E. A., and Jo, Y. K. (2019b). Host-mediated microbiome engineering (HMME) of drought tolerance in the wheat rhizosphere. PLoS One 14:e0225933. doi: 10.1371/journal.pone. 0225933

Johansen, J. E., and Binnerup, S. J. (2006). Contribution of Cytophaga -like bacteria to the potential of turnover of carbon, nitrogen, and phosphorus by bacteria in the rhizosphere of barley (Hordeum vulgare L .). Microb. Ecol. 43, 298-306. doi: 10.1007/s00248-002-2006-z

Jorquera, M. A., Gabler, S., Inostroza, N. G., Acuña, J. J., Campos, M. A., MenezesBlackburn, D., et al. (2018). Screening and characterization of phytases from bacteria isolated from chilean hydrothermal environments. Microb. Ecol. 75, 387-399. doi: 10.1007/s00248-017-1057-0

Jorquera, M. A., Maruyama, F., Ogram, A. V., Navarrete, O. U., Lagos, L. M., Inostroza, N. G., et al. (2016). Rhizobacterial community structures associated with native plants grown in chilean extreme environments. Microb. Ecol. 72, 633-646. doi: 10.1007/s00248-016-0813-x

Kasotia, A., and Choudhary, D. K. (2014). "Role of endophytic microbes in mitigation of abiotic stress in plants," in Emerging Technologies and Management of Crop Stress Tolerance, ed. P. Ahmad (Cambridge, MA: Academic press).

Kearl, J., McNary, C., Lowman, J. S., Mei, C., Aanderud, Z. T., Smith, S. T., et al. (2019). Salt-tolerant halophyte rhizosphere bacteria stimulate growth of alfalfa in salty soil. Front. Microbiol. 10:1849. doi: 10.3389/fmicb.2019.01849

Kelly, C. R., Khoruts, A., Staley, C., Sadowsky, M. J., Abd, M., Alani, M., et al. (2016). Effect of fecal microbiota transplantation on recurrence in multiply 
recurrent clostridium difficile infection a randomized trial. Ann. Intern. Med. 165, 609-616. doi: 10.7326/M16-0271

Khan, N., Zandi, P., Ali, S., Mehmood, A., and Shahid, M. A. (2018). Impact of salicylic acid and PGPR on the drought tolerance and phytoremediation potential of helianthus annus. Front. Microbiol. 9:2507. doi: 10.3389/fmicb. 2018.02507

Komaresofla, B. R., Alikhani, H. A., Etesami, H., and Khoshkholgh-Sima, N. A. (2019). Improved growth and salinity tolerance of the halophyte Salicornia sp. by co-inoculation with endophytic and rhizosphere bacteria. Appl. Soil Ecol. 138, 160-170. doi: 10.1016/j.apsoil.2019.02.022

Kondou, Y., Miyagi, Y., Morito, T., Fujihira, K., Miyauchi, W., Moriyama, A., et al. (2019). Physiological function of photoreceptor UVR8 in UV-B tolerance in the liverwort Marchantia polymorpha. Planta 249, 1349-1364. doi: 10.1007/s00425019-03090-w

Kumar, J., Babele, P. K., Singh, D., and Kumar, A. (2016). UV-B Radiation stress causes alterations in whole cell protein profile and expression ofcertain genes in the rice phyllospheric bacterium Enterobacter cloacae. Front. Microbiol. 7:1440. doi: $10.3389 /$ fmicb. 2016.01440

Kumar, S., Sachdeva, S., Bhat, K. V., and Vats, S. (2018). "Plant responses to drought stress: physiological, biochemical and molecular basis," in Biotic and Abiotic Stress Tolerance in Plants, ed. S. Vats (Singapore: Springer).

Lakshmanan, V., Kitto, S. L., Caplan, J. L., Hsueh, Y. H., Kearns, D. B., Wu, Y. S., et al. (2012). Microbe-associated molecular patterns-triggered root responses mediate beneficial rhizobacterial recruitment in Arabidopsis. Plant Physiol. 160, 1642-1661. doi: 10.1104/pp.112.200386

Lata, R., Chowdhury, S., Gond, S. K., and White, J. F. (2018). Induction of abiotic stress tolerance in plants by endophytic microbes. Lett. Appl. Microbiol. 66, 268-276. doi: 10.1111/lam.12855

Lau, J. A., and Lennon, J. T. (2012). Rapid responses of soil microorganisms improve plant fitness in novel environments. Proc. Natl. Acad. Sci. U.S.A. 109, 14058-14062. doi: 10.1073/pnas.1202319109

Lev-Sagie, A., Goldman-Wohl, D., Cohen, Y., Dori-Bachash, M., Leshem, A., Mor, U., et al. (2019). Vaginal microbiome transplantation in women with intractable bacterial vaginosis. Nat. Med. 25, 1500-1504. doi: 10.1038/s41591-019-0600-6

Li, J., Meng, B., Chai, H., Yang, X., Song, W., Li, S., et al. (2019). Arbuscular mycorrhizal fungi alleviate drought stress in C3 (Leymus chinensis) and C4 (Hemarthria altissima) grasses via altering antioxidant enzyme activities and photosynthesis. Front. Plant Sci. 10:499. doi: 10.3389/fpls.2019.00499

Li, X., Jousset, A., de Boer, W., Carrión, V. J., Zhang, T., Wang, X., et al. (2019). Legacy of land use history determines reprogramming of plant physiology by soil microbiome. ISME J. 13, 738-751. doi: 10.1038/s41396-018-0300-0

Lim, C. W., Baek, W., Han, S. W., and Lee, S. C. (2013). Arabidopsis PYl8 plays an important role for ABA signaling and drought stress responses. Plant Pathol. J. 29, 471-476. doi: 10.5423/PPJ.NT.07.2013.0071

Lim, J. H., and Kim, S. D. (2013). Induction of drought stress resistance by multifunctional PGPR Bacillus licheniformis K11 in pepper. Plant Pathol. J. 29, 201-208. doi: 10.5423/PPJ.SI.02.2013.0021

Lindemann, S. R., Bernstein, H. C., Song, H., Fredrickson, J. K., Fields, M. W., Shou, W., et al. (2016). Engineering microbial consortia for controllable outputs. ISME J. 10, 2077-2084. doi: 10.1038/ismej.2016.26

Liu, C. Y., Srivastava, A. K., and Wu, Q. S. (2017). Mycorrhizal fungi regulate root responses and leaf physiological activities in trifoliate orange. Notulae Bot. Hortic. Agrobotanici Cluj-Napoca 45, 17-21. doi: 10.15835/nbha451 10658

Liu, Y., Chen, L., Wu, G., Feng, H., Zhang, G., Shen, Q., et al. (2017). Identification of root-secreted compounds involved in the communication between cucumber, the beneficial bacillus amyloliquefaciens, and the soil-borne pathogen fusarium oxysporum. Mol. Plant Microbe Interact. 30, 53-62. doi: 10.1094/MPMI-07-16-0131-R

Liu, G., Li, X., Jin, S., Liu, X., Zhu, L., Nie, Y., et al. (2014). Overexpression of rice NAC gene SNAC1 improves drought and salt tolerance by enhancing root development and reducing transpiration rate in transgenic cotton. PLoS One 9:e0086895. doi: 10.1371/journal.pone.0086895

Liu, Y., Zhang, N., Qiu, M., Feng, H., Vivanco, J. M., Shen, Q., et al. (2014). Enhanced rhizosphere colonization of beneficial Bacillus amyloliquefaciens SQR9 by pathogen infection. FEMS Microbiol. Lett. 353, 49-56. doi: 10.1111/ 1574-6968.12406
Liu, Z., Li, Y., Wang, J., He, X., and Tian, C. (2015). Different respiration metabolism between mycorrhizal and non-mycorrhizal rice under lowtemperature stress: a cry for help from the host. J. Agric. Sci. 153, 602-614. doi: 10.1017/S0021859614000434

Lundberg, D. S., Lebeis, S. L., Paredes, S. H., Yourstone, S., Gehring, J., Malfatti, S., et al. (2012). Defining the core Arabidopsis thaliana root microbiome. Nature 488, 86-90 doi: 10.1038/nature 11237

Madsen, E. L. (2011). Microorganisms and their roles in fundamental biogeochemical cycles. Curr. Opin. Biotechnol 22, 456-464. doi: 10.1016/j. copbio.2011.01.008

Mahmoud, O. M., Ben Slimene, I., Ben Zribi, O. T., Abdelly, C., and Djébali, N. (2017). Response to salt stress is modulated by growth-promoting rhizobacteria inoculation in two contrasting barley cultivars. Acta Physiol. Plant. 39:120. doi: 10.1007/s11738-017-2421-x

Makhalanyane, T. P., Valverde, A., Gunnigle, E., Frossard, A., Ramond, J. B., and Cowan, D. A. (2015). Microbial ecology of hot desert edaphic systems. FEMS Microbiol. Rev. 39, 203-221. doi: 10.1093/femsre/fuu011

Mapelli, F., Marasco, R., Rolli, E., Barbato, M., Cherif, H., Guesmi, A., et al. (2013). Potential for plant growth promotion of rhizobacteria associated with Salicornia growing in Tunisian hypersaline soils. Biomed Res. Int. 2013:248078. doi: 10.1155/2013/248078

Martinez-Viveros, O., Jorquera, M. A., Crowley, D. E., Gajardo, G., and Mora, M. L. (2010). Mechanisms and practical considerations involved in plant growth promotion by rhizobacteria. J. Soil Sci. Plant Nutr. 10, 293-319.

Marusenko, Y., Bates, S. T., Anderson, I., Johnson, S. L., Soule, T., and GarciaPichel, F. (2013). Ammonia-oxidizing archaea and bacteria are structured by geography in biological soil crusts across North American arid lands. Ecol. Process. 2, 1-10. doi: 10.1186/2192-1709-2-9

Massalha, H., Korenblum, E., Tholl, D., and Aharoni, A. (2017). Small molecules below-ground: the role of specialized metabolites in the rhizosphere. Plant J. 90, 788-807. doi: 10.1111/tpj.13543

Mathur, S., Tomar, R. S., and Jajoo, A. (2019). Arbuscular Mycorrhizal fungi (AMF) protects photosynthetic apparatus of wheat under drought stress. Photosynth. Res. 139, 227-238. doi: 10.1007/s11120-018-0538-4

Meddich, A., Jaiti, F., Bourzik, W., Asli, A., and El Hafidi, M. (2015). Use of mycorrhizal fungi as a strategy for improving the drought tolerance in date palm (Phoenix dactylifera). Sci. Hortic. 192, 468-474. doi: 10.1016/j.scienta. 2015.06.024

Meena, K. K., Sorty, A. M., Bitla, U. M., Choudhary, K., Gupta, P., Pareek, A., et al. (2017). Abiotic stress responses and microbe-mediated mitigation in plants: the omics strategies. Front. Plant Sci. 8:172. doi: 10.3389/fpls.2017. 00172

Mega, R., Abe, F., Kim, J. S., Tsuboi, Y., Tanaka, K., Kobayashi, H., et al. (2019). Tuning water-use efficiency and drought tolerance in wheat using abscisic acid receptors. Nat. Plants 5, 153-159. doi: 10.1038/s41477-019-0361-8

Melo, I., Souza, W., Silva, L., Santos, S., Assalin, M., Zucchi, T., et al. (2016). Antifungal activity of Pseudomonas frederiksbergensis CMAA 1323 isolated from the antarctic hair grass Deschampsia antarctica. Br. Microbiol. Res. J. 14, 1-11. doi: 10.9734/bmrj/2016/25314

Melusá, E., Sas-Paszt, L., and Ciesielska, J. (2012). Technologies for beneficialmicroorganisms inocula used as biofertilizers. Sci. World J. 2012:491206. doi: 10.1100/2012/491206

Mendes, L. W., Kuramae, E. E., Navarrete, A. A., Van Veen, J. A., and Tsai, S. M. (2014). Taxonomical and functional microbial community selection in soybean rhizosphere. ISME J. 8, 1577-1587. doi: 10.1038/ismej.2014.17

Mesa-Marín, J., Pérez-Romero, J. A., Mateos-Naranjo, E., Bernabeu-Meana, M., Pajuelo, E., Rodríguez-Llorente, I. D., et al. (2019). Effect of plant growthpromoting rhizobacteria on salicornia ramosissima seed germination under salinity, CO2 and temperature stress. Agronomy 9, 1-14. doi: 10.3390/ agronomy9100655

Mickan, B. S., Abbott, L. K., Solaiman, Z. M., Mathes, F., Siddique, K. H. M., and Jenkins, S. N. (2019). Soil disturbance and water stress interact to influence arbuscular mycorrhizal fungi, rhizosphere bacteria and potential for $\mathrm{N}$ and $\mathrm{C}$ cycling in an agricultural soil. Biol. Fertil. Soils 55, 53-66. doi: 10.1007/s00374018-1328-z

Miethling, R., Wieland, G., Backhaus, H., and Tebbe, C. C. (2000). Variation of microbial rhizosphere communities in response to crop species, soil origin, 
and inoculation with Sinorhizobium meliloti L33. Microb. Ecol. 40, 43-56. doi: $10.1007 / \mathrm{s} 002480000021$

Mishra, G., Zhang, W., Deng, F., Zhao, J., and Wang, X. (2006). A bifurcating pathway directs abscisic acid effects on stomatal closure and opening in Arabidopsis. Science 312, 264-266. doi: 10.1126/science.1123769

Mishra, S. K., Khan, M. H., Misra, S., Dixit, V. K., Khare, P., Srivastava, S., et al. (2017). Characterisation of Pseudomonas spp. and Ochrobactrum sp. isolated from volcanic soil. Antonie van Leeuwenhoek Int. J. Gen. Mol. Microbiol. 110, 253-270. doi: 10.1007/s10482-016-0796-0

Molina-Montenegro, M. A., Ballesteros, G. I., Castro-Nallar, E., Meneses, C., Gallardo-Cerda, J., and Torres-Díaz, C. (2019). A first insight into the structure and function of rhizosphere microbiota in Antarctic plants using shotgun metagenomic. Polar Biol. 42, 1825-1835. doi: 10.1007/s00300-019-02556-7

Molina-Montenegro, M. A., Oses, R., Torres-Díaz, C., Atala, C., Zurita-Silva, A., and Ruiz-Lara, S. (2016). Root-endophytes improve the ecophysiological performance and production of an agricultural species under drought condition. AoB Plants 8, 1-11. doi: 10.1093/aobpla/plw062

Mueller, C. A., Obermeier, M. M., and Berg, G. (2016). Bioprospecting plantassociated microbiomes. J. Biotechnol. 235, 171-180. doi: 10.1016/j.jbiotec.2016. 03.033

Mueller, U. G., and Sachs, J. L. (2015). Engineering microbiomes to improve plant and animal health. Trends Microbiol. 23, 606-617. doi: 10.1016/j.tim.2015.07. 009

Müller-Xing, R., Xing, Q., and Goodrich, J. (2014). Footprints of the sun: memory of UV and light stress in plants. Front. Plant Sci. 5:474. doi: 10.3389/fpls.2014. 00474

Naiman, A., Latrónico, A., and García de Salamone, I. (2009). Inoculation of wheat with Azospirillum brasilense and Pseudomonas fluorescens: impact on the production and culturable rhizosphere microflora. European Journal of Soil Biology, 45, 44-51. doi: 10.1016/j.ejsobi.2008.11.001

Niederberger, T. D., Bottos, E. M., Sohm, J. A., Gunderson, T., Parker, A., Coyne, K. J., et al. (2019). Rapid microbial dynamics in response to an induced wetting event in antarctic dry valley soils. Front. Microbiol. 10:621. doi: 10.3389/fmicb. 2019.00621

Niederberger, T. D., Sohm, J. A., Gunderson, T. E., Parker, A. E., Tirindelli, J., Capone, D. G., et al. (2015). Microbial community composition of transiently wetted antarctic dry valley soils. Front. Microbiol. 6:9. doi: 10.3389/fmicb.2015. 00009

Niu, B., Paulson, J., Zheng, X., and Kolter, R. (2017). Simplified and representative bacterial community of maize roots. Proc. Natl. Acad. Sci. U.S.A. 114, E2450E2459. doi: 10.1073/pnas.1616148114

Niu, X., Song, L., Xiao, Y., and Ge, W. (2018). Drought-tolerant plant growthpromoting rhizobacteria associated with foxtail millet in a semi-arid and their potential in alleviating drought stress. Front. Microbiol. 8:2580. doi: 10.3389/ fmicb.2017.02580

Novotná, K., Klem, K., Holub, P., Rapantová, B., and Urban, O. (2016). Evaluation of drought and UV radiation impacts on above-ground biomass of mountain grassland by spectral reflectance and thermal imaging techniques. Beskydy 9 , 21-30. doi: 10.11118/beskyd201609010021

Orozco-Mosqueda, M. D. C., Rocha-Granados, M. D. C., Glick, B. R., and Santoyo, G. (2018). Microbiome engineering to improve biocontrol and plant growthpromoting mechanisms. Microbiol. Res. 208, 25-31. doi: 10.1016/j.micres.2018. 01.005

Panke-Buisse, K., Poole, A. C., Goodrich, J. K., Ley, R. E., and Kao-Kniffin, J. (2015). Selection on soil microbiomes reveals reproducible impacts on plant function. ISME J. 9, 980-989. doi: 10.1038/ismej.2014.196

Paramsothy, S., Kamm, M. A., Kaakoush, N. O., Walsh, A. J., van den Bogaerde, J., Samuel, D., et al. (2017). Multidonor intensive faecal microbiota transplantation for active ulcerative colitis: a randomised placebo-controlled trial. Lancet 389, 1218-1228. doi: 10.1016/S0140-6736(17)30182-4

Pieterse, C. M. J., Zamioudis, C., Berendsen, R. L., Weller, D. M., Van Wees, S. C. M., and Bakker, P. A. H. M. (2014). Induced systemic resistance by beneficial microbes. Annu. Rev. Phytopathol. 52, 347-375. doi: 10.1146/ annurev-phyto-082712-102340

Pratap, D., Harikesh, S., Singh, B., and Prabha, R. (2016). Microbial inoculants in sustainable agricultural productivity. Front. Microbiol. 7:2105. doi: 10.3389/ fmicb.2016.02105
Pudasaini, S., Wilson, J., Ji, M., van Dorst, J., Snape, I., Palmer, A. S., et al. (2017). Microbial diversity of browning Peninsula, Eastern Antarctica revealed using molecular and cultivation methods. Front. Microbiol. 8:591. doi: 10.3389/fmicb. 2017.00591

Ramírez, V., Coego, A., López, A., Agorio, A., Flors, V., and Vera, P. (2009). Drought tolerance in Arabidopsis is controlled by the OCP3 disease resistance regulator. Plant J. 58, 578-591. doi: 10.1111/j.1365-313X.2009.03804.x

Ramos, P., Rivas, N., Pollmann, S., Casati, P., and Molina-Montenegro, M. A. (2018). Hormonal and physiological changes driven by fungal endophytes increase Antarctic plant performance under UV-B radiation. Fung. Ecol. 34, 76-82. doi: 10.1016/j.funeco.2018.05.006

Rascovan, N., Carbonetto, B., Perrig, D., Díaz, M., Canciani, W., Abalo, M., et al. (2016). Integrated analysis of root microbiomes of soybean and wheat from agricultural fields. Sci. Rep. 6, 1-12. doi: 10.1038/srep28084

Raza, A., Razzaq, A., Mehmood, S., Zou, X., Zhang, X., Lv, Y., et al. (2019). Impact of climate change on crops adaptation and strategies to tackle its outcome: a review. Plants 8:34. doi: 10.3390/plants8020034

Robson, T. M., Klem, K., Urban, O., and Jansen, M. A. K. (2015). Re-interpreting plant morphological responses to UV-B radiation. Plant Cell Environ. 38, 856-866. doi: 10.1111/pce.12374

Rolfe, S. A., Griffiths, J., and Ton, J. (2019). Crying out for help with root exudates: adaptive mechanisms by which stressed plants assemble health-promoting soil microbiomes. Curr. Opin. Microbiol. 49, 73-82. doi: 10.1016/j.mib.2019.10.003

Rudrappa, T., Czymmek, K. J., Paré, P. W., and Bais, H. P. (2008). Root-secreted malic acid recruits beneficial soil bacteria. Plant Physiol. 148, 1547-1556. doi: 10.1104/pp.108.127613

Sahay, H., Mahfooz, S., Singh, A. K., Singh, S., Kaushik, R., Saxena, A. K., et al. (2012). Exploration and characterization of agriculturally and industrially important haloalkaliphilic bacteria from environmental samples of hypersaline Sambhar lake, India. World J. Microbiol. Biotechnol. 28, 3207-3217. doi: 10. 1007/s11274-012-1131-1

Salamone, I. E. G., De Funes, J. M., Di Salvo, L. P., Escobar-Ortega, J. S., D’Auria, F., Ferrando, L., et al. (2012). Inoculation of paddy rice with Azospirillum brasilense and Pseudomonas fluorescens: impact of plant genotypes on rhizosphere microbial communities and field crop production. Appl. Soil Ecol. 61, 196-204. doi: 10.1016/j.apsoil.2011.12.012

Salamone, I. E. G., De Salvo, L. P., and Di Ortega, J. S. E. (2010). Field response of rice paddy crop to Azospirillum inoculation: physiology of rhizosphere bacterial communities and the genetic diversity of endophytic bacteria in different parts of the plants. Plant Soil 351-362. doi: 10.1007/s11104-010-0487-y

Santiago, I. F., Rosa, C. A., and Rosa, L. H. (2017). Endophytic symbiont yeasts associated with the Antarctic angiosperms Deschampsia antarctica and Colobanthus quitensis. Polar Biol. 40, 177-183. doi: 10.1007/s00300-0161940-z

Santoyo, G., Hernández-Pacheco, C., Hernández-Salmerón, J., and HernándezLeón, R. (2017). The role of abiotic factors modulating the plant-microbe-soil interactions: toward sustainable agriculture. A review. Span. J. Agric. Res. 15:e03R01. doi: 10.5424/sjar/2017151-9990

Sharma, S., Chatterjee, S., Kataria, S., Joshi, J., Datta, S., Vairale, M. G., et al. (2017). A review on responses of plants to UV-B radiation related stress. UV-B Radiat. 2070, 75-97. doi: 10.1002/9781119143611.ch5

Sheth, R. U., Cabral, V., Chen, S. P., and Wang, H. H. (2016). Manipulating bacterial communities by in situ microbiome engineering. Trends Genet. 32, 189-200. doi: 10.1016/j.tig.2016.01.005

Singh, B. K., Bardgett, R. D., Smith, P., and Reay, D. S. (2010). Microorganisms and climate change: terrestrial feedbacks and mitigation options. Nat. Rev. Microbiol. 8, 779-790. doi: 10.1038/nrmicro2439

Stomeo, F., Valverde, A., Pointing, S. B., McKay, C. P., Warren-Rhodes, K. A., Tuffin, M. I., et al. (2013). Hypolithic and soil microbial community assembly along an aridity gradient in the Namib Desert. Extremophiles 17, 329-337. doi: 10.1007/s00792-013-0519-7

Sun, J., Hu, W., Zhou, R., Wang, L., Wang, X., Wang, Q., et al. (2015). The Brachypodium distachyon BdWRKY36 gene confers tolerance to drought stress in transgenic tobacco plants. Plant Cell Rep. 34, 23-35. doi: 10.1007/s00299014-1684-6

Teixeira, L. C. R. S., Peixoto, R. S., and Rosado, A. S. (2013). Bacterial diversity in rhizosphere soil from antarctic vascular plants of admiralty bay in 
maritime Antarctica. Mol. Microb. Ecol. Rhizosphere 2, 1105-1112. doi: 10.1002/ 9781118297674.ch105

Timmusk, S., Abd El-Daim, I. A., Copolovici, L., Tanilas, T., Kännaste, A., Behers, L., et al. (2014). Drought-tolerance of wheat improved by rhizosphere bacteria from harsh environments: enhanced biomass production and reduced emissions of stress volatiles. PLoS One 9:e0096086. doi: 10.1371/journal.pone. 0096086

Timmusk, S., Behers, L., Muthoni, J., Muraya, A., and Aronsson, A. C. (2017). Perspectives and challenges of microbial application for crop improvement. Front. Plant Sci. 8:49. doi: 10.3389/fpls.2017.00049

Tkacz, A., Cheema, J., Chandra, G., Grant, A., and Poole, P. S. (2015). Stability and succession of the rhizosphere microbiota depends upon plant type and soil composition. ISME J. 9, 2349-2359. doi: 10.1038/ismej.2015.41

Toju, H., Okayasu, K., and Notaguchi, M. (2018a). Network hubs in root-associated fungal metacommunities. Microbiome 6:116. doi: 10.1186/s40168-018-0497-1

Toju, H., Peay, K. G., Yamamichi, M., Narisawa, K., Hiruma, K., Naito, K., et al. (2018b). Core microbiomes for sustainable agroecosystems. Nat. Plants 4, 247-257. doi: 10.1038/s41477-018-0139-4

Torres-Díaz, C., Gallardo-Cerda, J., Lavin, P., Oses, R., Carrasco-Urra, F., Atala, C., et al. (2016). Biological interactions and simulated climate change modulates the ecophysiological performance of Colobanthus quitensis in the Antarctic ecosystem. PLoS One 11:e0164844. doi: 10.1371/journal.pone.0164844

Tossi, V. E., Regalado, J. J., Iannicelli, J., Laino, L. E., Burrieza, H. P., Escandón, A. S., et al. (2019). Beyond Arabidopsis: differential UV-B response mediated by UVR8 in diverse species. Front. Plant Sci. 10:780. doi: 10.3389/fpls.2019.00780

Trabelsi, D., Mengoni, A., Ben Ammar, H., and Mhamdi, R. (2011). Effect of on-field inoculation of Phaseolusvulgariswith rhizobia on soil bacterial communities. FEMS Microbiol. Ecol. 77, 211-222. doi: 10.1111/j.1574-6941. 2011.01102.x

Trivedi, P., Schenk, P. M., Matthew, D., and Singh, B. K. (2017). Tiny Microbes, big yields: enhancing food crop production with biological solutions. Microb. Biotechnol. 10, 999-1003. doi: 10.1111/1751-7915.12804

Ullah, S., Khan, M. Y., Asghar, H. N., Akhtar, M. J., and Zahir, Z. A. (2017). Differential response of single and co-inoculation of Rhizobium leguminosarum and Mesorhizobium ciceri for inducing water deficit stress tolerance in wheat. Ann. Microbiol. 67, 739-749. doi: 10.1007/s13213-017-1302-2

United Nations (2019). Department of Economic and Social Affairs, Population Division. World Population Prospects 2019: Highlights (ST/ESA/SER.A/423). New York, NY: United Nations.

Upson, R., Read, D. J., and Newsham, K. K. (2009). Nitrogen form influences the response of Deschampsia antarctica to dark septate root endophytes. Mycorrhiza 20, 1-11. doi: 10.1007/s00572-009-0260-3

Vidiella, P. E., Armesto, J. J., and Gutiérrez, J. R. (1999). Vegetation changes and sequential flowering after rain in the southern Atacama Desert. J. Arid Environ. 43, 449-458. doi: 10.1006/jare.1999.0565

Viscardi, S., Ventorino, V., Duran, P., Maggio, A., De Pascale, S., Mora, M. L., et al. (2016). Assessment of plant growth promoting activities and abiotic stress tolerance of Azotobacter chroococcum strains for a potential use in sustainable agriculture. J. Soil Sci. Plant Nutr. 16, 848-863.

Vurukonda, S. S. K. P., Vardharajula, S., Shrivastava, M., and SkZ, A. (2016). Enhancement of drought stress tolerance in crops by plant growth promoting rhizobacteria. Microbiol. Res. 184, 13-24. doi: 10.1016/j.micres.2015.12.003

Wang, J., Vanga, S. K., Saxena, R., Orsat, V., and Raghavan, V. (2018). Effect of climate change on the yield of cereal crops: a review. Climate 6:41. doi: 10.3390/cli6020041

Wang, W., Cao, X. H., Miclau, M., Xu, J., and Xiong, W. (2017). The promise of agriculture genomics. Int. J. Genom. 2017:9743749. doi: 10.1155/2017/974 3749

Wang, Y., Yu, G., Li, K., Wu, M., Ma, J., Xu, J., et al. (2015). Responses of photosynthetic properties and antioxidant enzymes in high-yield rice flag leaves to supplemental UV-B radiation during senescence stage. Environ. Sci. Pollut. Res. 22, 4695-4705. doi: 10.1007/s11356-014-3714-x

Woo, S. L., and Pepe, O. (2018). Microbial consortia: promising probiotics as plant biostimulants for sustainable agriculture. Front. Plant Sci. 9:1801. doi: 10.3389/fpls.2018.01801

Wu, X., Xie, Y., Qiao, J., Chai, S., and Chen, L. (2019). Rhizobacteria strain from a hypersaline environment promotes plant growth of Kengyilia thoroldiana. Microbiology 88, 220-231. doi: 10.1134/S0026261719020127

Yadav, A. N., Sachan, S. G., Verma, P., and Saxena, A. K. (2016). Bioprospecting of plant growth promoting psychrotrophic bacilli from the cold desert of north western indian himalayas. Indian J. Exp. Biol. 54, 142-150.

Yang, G., Yu, L., Zhang, K., Zhao, Y., Guo, Y., and Gao, C. (2017). A ThDREB gene from Tamarix hispida improved the salt and drought tolerance of transgenic tobacco and T. hispida. Plant Physiol. Biochem. 113, 187-197. doi: 10.1016/j. plaphy.2017.02.007

Yang, Y., Yang, X., Jang, Z., Chen, Z., Ruo, X., Jin, W., et al. (2018). UV RESISTANCE LOCUS 8 from chrysanthemum morifolium ramat (CmUVR8) plays important roles in UV-B signal transduction and UV-B-induced accumulation of flavonoids. Front. Plant Sci. 9:955. doi: 10.3389/fpls.2018. 00955

Yao, X., Xiong, W., Ye, T., and Wu, Y. (2012). Overexpression of the aspartic protease ASPG1 gene confers drought avoidance in Arabidopsis. J. Exp. Bot. 63, 2579-2593. doi: 10.1093/jxb/err433

Yarzábal, L. A., Monserrate, L., Buela, L., and Chica, E. (2018). Antarctic Pseudomonas spp. promote wheat germination and growth at low temperatures. Polar Biol. 41, 2343-2354. doi: 10.1007/s00300-018-2374-6

Yergeau, E., Bell, T. H., Champagne, J., Maynard, C., Tardif, S., Tremblay, J., et al. (2015). Transplanting soil microbiomes leads to lasting effects on willow growth, but not on the rhizosphere microbiome. Front. Microbiol. 6:1436. doi: 10.3389/fmicb.2015.01436

Zhao, M., Xue, K., Wang, F., Liu, S., Bai, S., and Sun, B. (2014). Microbial mediation of biogeochemical cycles revealed by simulation of global changes with soil transplant and cropping. ISME J. 8, 2045-2055. doi: 10.1038/ismej. 2014.46doi: 10.1038/ismej.2014.46

Zhou, R., Kong, L., Wu, Z., Rosenqvist, E., Wang, Y., Zhao, L., et al. (2019). Physiological response of tomatoes at drought, heat and their combination followed by recovery. Physiol. Plant. 165, 144-154. doi: 10.1111/ppl. 12764

Zhou, R., Yu, X., Ottosen, C. O., Rosenqvist, E., Zhao, L., Wang, Y., et al. (2017). Drought stress had a predominant effect over heat stress on three tomato cultivars subjected to combined stress. BMC Plant Biol. 17:24. doi: 10.1186/ s12870-017-0974-X

Zhu, B., Wang, X., and Li, L. (2010). Human gut microbiome: the second genome of human body. Protein Cell 1, 718-725. doi: 10.1007/s13238-010-0093-z

Zubair, M., Hanif, A., Farzand, A., Sheikh, T. M. M., Khan, A. R., Suleman, M., et al. (2019). Genetic screening and expression analysis of psychrophilic bacillus spp. Reveal their potential to alleviate cold stress and modulate phytohormones in wheat. Microorganisms 7:337. doi: 10.3390/microorganisms 7090337

Conflict of Interest: The authors declare that the research was conducted in the absence of any commercial or financial relationships that could be construed as a potential conflict of interest.

Copyright (C) 2020 Rodriguez and Durán. This is an open-access article distributed under the terms of the Creative Commons Attribution License (CC BY). The use, distribution or reproduction in other forums is permitted, provided the original author(s) and the copyright owner(s) are credited and that the original publication in this journal is cited, in accordance with accepted academic practice. No use, distribution or reproduction is permitted which does not comply with these terms. 